\title{
LA RAIIZ Y CÚSPIDE DE LA INTELECCIÓN HUMANA: EL INTELECTO AGENTE. UNA COMPARACIÓN ENTRE TOMÁS DE AQUINO, BUENAVENTURA Y LEONARDO POLO
}

THE ROOT AND THE CUSP OF HUMAN INTELLECTION: AGENT INTELLECT. A COMPARISON BETWEEN THOMAS AQUINAS, ST. BONAVENTURE AND LEONARDO POLO

\author{
Juan Fernando Sellés ${ }^{1}$ \\ Universidad de Navarra (España)
}

Recibido: 13-03-2014

Aceptado: 14-07-2014

\begin{abstract}
Resumen: En este trabajo se expone que, para Tomás de Aquino, el intelecto agente es una potencia activa; que, para Buenaventura, es un hábito adquirido, mientras que L. Polo lo considera equivalente al acto de ser personal humano. Se estudia la coherencia de estas tesis, se comparan sus propuestas y su alcance. Palabras-clave: Intelecto agente, Tomás de Aquino, San Buenaventura, Leonardo Polo.
\end{abstract}

\begin{abstract}
In this work we compare the version of Thomas Aquinas' intellectus agens as one active potency, with the Bonaventure' opinion as one acquired habit, and also with the Polo's equivalence between the agent intellect with the human act of being. We study the internal coherence of those thesis and its implications.
\end{abstract}

Key-words: Agent intellect, Thomas Aquinas, St. Bonaventure, Leonardo Polo.

[1] (jfselles@unav.es) Profesor Titular de Antropología en la Facultad de Filosofía y Letras de la Universidad de Navarra. Sus dos líneas de investigación son la Antropología filosófica y la Teoría del conocimiento. 


\section{Introducción ${ }^{2}$}

Como es sabido, la obra del Doctor Angélico es extensa, y no menos la bibliografía sobre su pensamiento. En cambio, la del Doctor Seráfico es, en comparación con la precedente, breve, y también son menos los estudios sobre sus escritos. Por su parte, la de Leonardo Polo es amplia, a pesar de estar en buena medida inédita; $\mathrm{y}$, asimismo, los trabajos sobre su filosofía van progresivamente cada día en un paulatino 'in crescendo'. Al tema que nos ocupa -el intelecto agente- el de Aquino le dedicó algunos capítulos en 9 de sus libros, mientras que el parecer de Juan Fidenza cabe en una sola página. Por su parte, el de Polo, es asimismo extenso, pues aunque no le dedique ningún trabajo 'ex professo', su parecer sobre este punto está diseminado en multitud de lugares y obras, tanto de teoría del conocimiento como de antropología.

He tenido la oportunidad de estudiar este tema y de escribir al respecto sobre el parecer de cada uno de los tres aludidos autores ${ }^{3}$. En este trabajo intentaré, más bien, sintetizar su parecer y compararlos entre sí, a la vez que dirimir el alcance de sus respectivas propuestas. Se me ha aconsejado exponer este tema en estos tres pensadores porque en este número monográfico de Thé-

[2] Agradezco a Juan A. García la invitación a participar en este número monográfico de Thémata sobre el pensamiento del Profesor Leonardo Polo, recientemente fallecido (9-II-2013).

[3] Cfr. sobre este tema en Tomás de Aquino mis trabajos: "El lugar del entendimiento agente en la antropología de Tomás de Aquino", Actes del Simposi Internacional de Filosofía de l' Edat Mitjana, Vic-Gerona, 11-16-IV-1994, Patronat d'Estudis Osonencs, (1996), 412-418; "El intelecto agente y las instancias cognoscitivas menores. Una propuesta desde Tomás de Aquino", Angelicum, 82/3 (2005) 611-617; "El entendimiento agente según Tomás de Aquino", Revista Española de Filosofía Medieval, 9 (2002) 105-124; "La crítica tomista a la interpretación griega y neoplatónica del intelecto agente", Intellect et imagination dans la Philosophie Médiévale, Actes du XIe Congrès International de Philosophie Médiévale de la Société Internationale pour l'Étude de la Philosophie Médiévale (S.I.E.P.M.), Porto, 26-31-août-2002, Brepols, 2006, vol. III, 1389-1404; "Una propuesta del s. XIII muy seguida hasta hoy: el potencialismo de Tomás de Aquino", que conforma el Cap. VIII de mi libro El intelecto agente y los filósofos. Venturas y desventuras del supremo hallazgo aristotélico sobre el hombre, (I). Siglos IV a. C. - XV, Pamplona, Eunsa, 2012, 241-275.

Sobre este tema en San Buenaventura he tratado en "El intelecto agente en los maestros franciscanos del s. XIII", Verdad y vida, LXIII/242 (2005) 127-148; y también en el citado libro de El intelecto agente y los filósofos, Cap. X: "El habitualismo de los siglos XIII y XIV: Buenaventura y Alfonso de Toledo", Op. cit., 313-317. Cfr. también mi trabajo: "Los filósofos del s. XIII que afirmaron el intelecto agente", Anuario de Estudios Medievales CSIC, 38/1 (2008), 445-474.

$\mathrm{Al}$ estudio de este tema en $\mathrm{L}$. Polo he dedicado varios artículos y un libro. Entre los primeros cabe destacar: "¿Personalización o despersonalización del intelecto agente. Polo y los filósofos árabes Avicena y Averroes", Studia Poliana, 5 (2003) 147-165; "El conocer como acto de ser", Cuadernos de Pensamiento, 17 (2005) 283-295; "Trascendentalidad y tema del conocer personal", Pensamiento, 62/223 (2006) 329-343; "El intelecto agente como acto de ser personal", Logos. Anales del Seminario de Metafísica, 45 (2012) 35-63; "El acceso a Dios del conocer personal humano", Studia Poliana, 14 (2012) 83-117. El libro lleva por título El conocer personal. Estudio del entendimiento agente según Leonardo Polo, Cuadernos de Anuario Filosófico, Serie Universitaria, $\mathrm{n}^{\circ}$ 163, Pamplona, Servicio de Publicaciones de la Universidad de Navarra, 2003.

THÉMATA. Revista de Filosofía, Nº50 julio-diciembre (2014) pp.: 113-134 doi: 10.12795/themata.2014.i50.05 
mata, en el que se pretende trabajar la intelección según Leonardo Polo y comparar su propuesta con la otros relevantes pensadores, estimo que el intelecto agente es la cima del conocer humano; además, es conveniente atender a los tres autores mencionados porque gozan de un justo y reconocido prestigio en la historia de la filosofía. Es conveniente contrastar también su parecer sobre el intelecto agente porque cada uno defiende una de las tres propuestas más fundadas que sobre este tema ha habido a lo largo de la historia de la filosofía.

En efecto, dejando al margen las tesis extravagantes del sustancialismo ${ }^{4}$ y del panpsiquismo ${ }^{5}$, y rechazando asimismo la más divulgada propuesta de su negación que, siendo de candente actualidad ${ }^{6}$, y que estando en sintonía con el formalismo escotista ${ }^{7}$ y con el nominalismo ockhamista ${ }^{8}$

[4] Designamos como sustancialismo la versión que defendió que el intelecto agente es una 'sustancia', la cual admitió dos variantes en la historia de la filosofía:

a) La de entender al intelecto agente como 'sustancia separada', al estilo los comentadores aristotélicos griegos (Alejandro de Afrodisia, Plotino, Temistio), árabes (Al-Kindi, Al-Farabí, Avicena, Algacel, Avempace, Averroes), judíos (Isaac Israelí, Avicebrón, Maimónides) y cristianos del s. XIII (Guillermo de Auvernia, Roger Bacon, Roger Marston, Siger de Brabante). Esta posición la mantuvieron posteriormente los siguientes autores: en los siglos XIV, Juan de Jandún, Marsilio de Padua, Mateo de Eugubio, Anselmo de Cumis, Juan Wenceslao de Praga, Moisés de Narbona, Jacobo de Placentia; en el s. XV, Pablo de Venecia, Gaetano de Thiene, Pedro Pomponazzi, Elías el Mendigo, Nicoletto Vernias; en el s. XVI, Agostino Nifo, Basciani Landi Placentani, Marco Antonio de Passeri, Antonii Scayni Salodiensis, Nicolai Finetti Senensis, Tiberii Bacilery, Jacopo Zabarella; en el s. XVII, Francisci Augustini Pallavicini; en el s. XIX, Adolph Trendelenburg, Guilelmus Biehl; en el s. XX, J. D. García Bacca, F. Nuyens, C. Schmidt Andrade, R. A. Herrera, Víctor Caston; en el s. XXI, Diego Sánchez Meca.

b) La de comprenderlo como 'sustancia humana' o 'forma' de ella, al estilo de los defensores del llamado 'hilemorfismo universal': Alejandro de Hales, Juan de la Rochela, Mateo de Aquasparta.

[5] Un comentador griego del Estagirita consideró que el intelecto agente es el alma de la humanidad, una para todo el género humano: Filopón. Este parecer se ciñe en exclusiva a dicho comentador griego.

[6] La mayor parte de los autores que actualmente tratan de teoría del conocimiento no distinguen realmente entre intelecto agente e intelecto posible. De este parecer fueron, en el s. XIII, Roberto Grosseteste, Pedro Juan Olivi, Gonzalo de España; en el s. XIV, Durando. De este estilo fueron las opiniones de Francisco Suárez y Gabriel Vázquez en el s. XVI. Pero, obviamente, ha sido una opinión tan generalizada como poco fundada en los ss. XX y XXI.

[7] Escoto admitió solamente una distinción 'formal' entre intelecto agente y posible. Su parecer fue seguido en el s. XIV por Ramón Llull, Guillermo Alnwick, Gregorio de Rímini, Tomás de Bailly, Teodoro Métochite; en el s. XVII, por Juan Merinero, Francisco Alfonso Malpartida, Michaele de Villaverde, Francisco De Oviedo Madritani, Angelo de Sonneno, Ioanne Antonio Ambrosino, Illuminato de Oddo, Bartolomaei Mastri de Meldula, Bonaventurae Belluti de Catana, Pedro de Santa Catalina; en el s. XXI, mantienen esta posición, entre otros, A. Vigo y Lloyd P. Gerson.

[8] Ockham defendió que entre intelecto agente y posible sólo se da una distinción 'nominal'. Esa tesis la mantuvieron en el s. XIV Juan de Buridán, Nicolás de Autrecourt, Pedro de Ailly, Adam de Wodeham, Nicolás Oresmes, Francisco de Marchia, Biagio Pelacani de Parma; en el s. XV, Alfonso Fernández de Madrigal ('el Tostado'), Gabriel Biel; en el s. XVI, Felipe Melanchton, Tomás Bricot; en el s. XVII, Andrés Landon, Juan de Lugo, Dionisio Blasco, Jualian Castelui y Ladron, Ignacio

THÉMATA. Revista de Filosofía, $\mathrm{N}^{\circ} 50$ julio-diciembre (2014) pp.: 113-134

doi: 10.12795/themata.2014.i50.05 
carece de fundamentación, las tres versiones más fundadas a lo largo del pensamiento occidental han sido las que lideran los tres autores que, sintéticamente, vamos a exponer. A la posición de Tomás de Aquino se la puede denominar potencialismo, porque sostiene que el intelecto agente es una 'potencia' distinta, por activa y superior, al intelecto posible o inteligencia; esta tesis ha sido muy seguida en los siglos posteriores al Aquinate ${ }^{9}$. Por su parte, a la versión propia de Buenaventura se la puede denominar habitualismo, porque defiende que el intelecto agente es un hábito. En contraste con la tomista, la opinión bonaventuriana carece de seguidores ${ }^{10}$. Por su parte, Leonardo Polo sostiene que el intelecto agente equivale al acto de ser personal humano, es decir, al conocer personal o conocer a nivel de 'actus essendi'. De este mismo parecer ha habido pocos defensores y todos ellos muy recientes ${ }^{11}$. Por lo demás, mi opinión al respecto la he expuesto en uno de los trabajos citados más arriba ${ }^{12}$.

Francisco Peynado, Francisco Murcia de la Llana, R. P. Fr. Martinus a Torrecilla; en el s. XVIII, Juan Gabriel Boyvin, V. González Peña, Juan de Urquizu, Gaspar Buhon, Ignacio Ponce Vacca, Crescente Krisper; en el s. XX, Nicolás Mónaco, Ángel Amor Ruibal, José Fröbes, J. P. Manyá, A. Bremond, André Marc, A. Willwoll, J. Muñoz.

[9] Esta tesis la siguieron, en el s. XIV, Gil de Roma, Radolfo Brito, Walter Burley, Gomes de Lisboa, Ricardo de Mediavilla, Bertram von Ahlen, Heinrich von Lübeck; en el s. XV, Dionisio el Cartujano, Juan Versor, Cristóforo Landino Pedro Níger, Nicolás Tignosius, Lamberti de Monte, Domingo de Flandes, Juan de Mechlinia, Juan de Glogowia, Ofredo Apolinar Cremonense, Crisostomo Iavelli, Joannes de Lutria, Silvestre de Ferrara, Cayetano; en el s. XVI, Rodrigo de Santa Ella, Miguel de Palacio, Sebastián Pérez, Francisco de Toledo, Pedro Martínez de Toledo y Brea, los comentadores Conimbricenses, Diego de Zúñiga, Domingo Báñez, Lucilii Philalthai, Niccolo Finetti, Francisco Pisa, Antonii Montecatini Ferrariensis, Vincentius Quintianus Brixiensi, Chrysostomi Iavelli Canapicii, Petri de Bruxellis; en el s. XVII, Paulo Soncinatis, Juan Martínez de Prado, Juan Cano, los comentadores Complutenses, Juan de Sto. Tomás, Francisco Palanco Campo, Antonio Rubio, Jacobo Fournenc, Nicolás Arnou, Silvestre Mauro, Cosme de Lerma; en el s. XVIII, el Colegio Ripense, José De Aguilera Salmanticensi, Pablo Aler, Juan Hidalgo Astigiensi, Antonio Iribarren Bilbilitani; en el s. XIX, Sancti Schiffini, Bernardo Boedder, Antonio Goudin Lemovicensi, S. Tongiorgi, T. Pesch; en el s. XX, E. Hugon, Th. M. Zigliara, W. D. Ross, Marcello a Puero Jesu, J. J. Urráburu, A. Farges, D. Barbedette, J. Donat, J. Mercier, S. Cantin, Gredt, V. Remer, I. di Napoli, C. Boyer, J. Hellín, F. Palmes, P. Siwek, R. Reyna, F. C. Peccorini, O. N. Derisi, P. Lee, B. R. Nelly.

[10] Sólo conozco otro autor, además de Buenaventura, que defienda esa posición, a saber, Alfonso de Toledo (s. XIV). La tesis de éste último pensador es, sin embargo, más fundada que la de Juan Fidenza, pues sostiene que se trata de un hábito innato, no de un hábito adquirido.

[11] Se encuadran en los siglos XX y XXI: F. Canals Vidal, García del Muro, Ignacio Falgueras, R. Yepes, J. A. García González, S. Piá Tarazona y J. I. Murillo.

[12] Cfr. "El acceso a Dios del conocer personal humano", Studia Poliana, 14 (2012) 83-117.

THÉMATA. Revista de Filosofía, №50 julio-diciembre (2014) pp.: 113-134 doi: 10.12795/themata.2014.i50.05 


\section{Las tesis centrales de Tomás de Aquino sobre el intelecto agente}

El Doctor Communis trató del intelecto agente -al margen de otras referencias sueltas y esporádicas-, en 9 escritos relevantes, que por orden cronológico son los siguientes: el Comentario a las Sentencias ${ }^{13}$ (1252-56), las Cuestiones Disputadas sobre la Verdad ${ }^{14}$ (1256-59), varios lugares de la Suma Contra los Gentiles ${ }^{15}$ (1259-65), las Cuestiones Disputadas sobre el Alma ${ }^{16}$ (1265-66), el Compendio de Teología ${ }^{17}$ (1267), las Cuestiones Disputadas Sobre las Criaturas Espirituales ${ }^{18}$ (1267-68), el Comentario al libro III Sobre el Alma ${ }^{19}$ (1267-68), el opúsculo Sobre la Unidad del Intelecto contra los averroístas $^{20}$ (1279), y la Suma Teológica ${ }^{21}$ (1273).

Tomás conoció casi toda la tradición precedente respecto de este tema. Desde luego estuvo al corriente de la distinción aristotélica del pasaje $D e$ anima III, 5. También estuvo al tanto de las versiones de los siguientes comentadores griegos: Teofrasto de Eresa, Alejandro de Afrodisia, Temistio, Juan Filopón. Supo de la interpretación árabe y judía medieval, es decir, la de Avicena, Averroes, Algacel, Isaac Israelí, Avicebrón y Maimónides. Para él, tanto hermenéutica griega como árabe y judía es de índole platónica. Supo también cómo se pronunciaron al respecto los diversos pensadores cristianos de su misma centuria, a saber: Alejandro de Hales, Alberto Magno, Guillermo de Auvernia, Buenaventura y Siger de Brabante. Hasta la primera mitad del siglo XIII dominaba la opinión de reducir el intelecto agente a la inteligencia. Tras la segunda mitad predominó el averroísmo latino y al final de ese siglo destacó de nuevo la tendencia a no distinguirlo del entendimiento posible o inteligencia.

Las tesis de Tomás de Aquino sobre el intelecto agente se pueden sintetizar en tres, de las cuales una queda referida a su modo de ser, otra a su índole noética, y la tercera a su relación con el posible y las demás dimensiones noéticas humanas.

[13] Cfr. Tomás De Aquino, In II Sent., d. 17, q. 2, a. 1.

[14] Cfr. De Ver., q. 10, a. 6.

[15] Cfr. S. C. Gentes, 1. II, caps. 76, 77 y 78; 1. III, caps. 42, 43, 44 y 45.

[16] Cfr. Q.D. De Anima, qq. 4 y 5.

[17] Cfr. Compendium Theologiae, lb. I, cap. 83.

[18] Cfr. De Spirit. Creat., q. un., a. 10.

[19] Cfr. In De Anima, l. III, lc. 10.

[20] Cfr. De Unitate Intellectus, caps. I-V.

[21] Cfr. S. Theol., I ps., q. 79, aa. 3, 4 y 5.

THÉMATA. Revista de Filosofía, Nº50 julio-diciembre (2014) pp.: 113-134 doi: 10.12795/themata.2014.i50.05 
a) 'El intelecto agente es una potencia'22. El fulcro de la doctrina tomista sobre el intelecto agente parece estribar en la noción de 'potencia activa'23, aunque en algún pasaje lo considera como $a c t o^{24}$. Como entiende que, en sentido estricto, una 'facultad' es un 'accidente', entiende que el intellectus agens es algo del hombre, no la persona humana. Tomás de Aquino escribió que el intelecto agente es 'algo'25, 'parte'26, 'potencia'27, 'virtud'28, 'accidente'29 del alma; y, por esto, sostuvo que se funda (como el posible) en la esencia del alma. Lo considera, como al posible, como una potencia humana sin soporte orgánico ${ }^{30}$ y distinta del posible, pero añade que se parece más al hábito que a la potencia (pues se distingue de la privación y de la potencia) ${ }^{31}$. Por tanto, pertenece -como el posible- a esa parcela del alma que es separada, es decir, no dependiente del cuerpo y, en consecuencia, forma parte del alma inmortal y perpetua, lo cual significa que, si bien el intelecto agente empieza a existir con el cuerpo (es connatural y originario en $\operatorname{nosotros}^{32}$ ), sin embargo, sobrevive a él, y sigue conociendo cuando éste perece. Lo que precede indica que el de Aquino admite -frente al sustancialismo-que el intelecto agente es uno en cada hombre. En efecto, el intelecto agente no es uno para todos los hombres; por tanto, ni es sustancia separada, ni es Dios. Tomás indica asimismo que es, con el posible, forma de nosotros ('forma nobis's3), pero que es forma del cuerpo en un sentido distinto (principio finito) a como es principio de operaciones intelectuales (infinito). Su acción le es concomitante, pero no existe identidad real entre él y su acción.

[22] Cfr. In II Sent., d. 17, q. 2, a. 1, co; S.C. Gentes, 1. II, cap. 77, n. 2. El intelecto agente, "no es separado en cuanto que es parte o potencia del alma, que es acto sustancial del cuerpo". De unitate intellectus, cap. 1.

[23] "Entre todas las potencias del alma no son activas sino el intelecto". Q. D. De Virt., q. 1, a. 3, ad. 5. Cfr. J. E., Royce, "St. Thomas and the Definition of Active Potency", The New Scholasticism, 34 (1960) 431-437; H. P. KaInz, Active and Passive Potency in Thomistic Angelology, Nijhoff, The Hague, 1972.

[24] "Se requiere en nosotros un principio activo propio, por el cual lleguemos a ser inteligentes en acto, y éste es el intelecto agente”. Q. D. De Anima, q. un., a. 5, co.

[25] Cfr. S.C. Gentes, 1. II, cap. 76, n. 17; Q.D. De Anima, q. un., a. 5, co; Q.D. De Spiritualibus creaturis, q. 10, co; De unitate intellectus., cap. 1; S. Theol., I ps., q. 79, a. 4 co.

[26] Cfr. In De Anima, 1. III, lc. 10. n. 5.

[27] Cfr. S. Theol., I ps., q. 79, a. 4 co ad 5.

[28] Cfr. S. Theol., I ps., q. 79, a. 5, co.

[29] Cfr. Comp. Theol., I ps., cap. 88.

[30] Cfr. S.C. Gentes, 1. II, cap. 79, n. 9; Q. D. De Anima, q. un, a. 5, ad 4; Comp. Theol., I ps., cap. 89; Q.D. De Spiritualibus creaturis, q. 11, ad 20; In De Anima., 1. III, lc. 10, n. 5; De unitate intellectus., cap. 1.

[31] S.C. Gentes, 1. II, cap. 78, nn. 2, 5 y 7.

[32] Cfr. S. C. Gentes, 1. II, cap. 77, n. 4.

[33] Compendium Theologiae, I ps., cap. 86.

THÉMATA. Revista de Filosofía, ${ }^{\circ} 50$ julio-diciembre (2014) pp.: 113-134

doi: 10.12795/themata.2014.i50.05 
b) 'El intelecto agente es luz cognoscitiva innata que procede directamente de Dios y está abierto a conocer la totalidad de lo real ${ }^{34}$. Por él conocemos todo lo que podemos conocer, y según él discernimos lo verdadero de lo falso, y lo bueno de lo malo. Es un desbordamiento en nosotros de la perfección divina; cierta participación de la luz intelectual de las sustancias separadas, en especial, de Dios; virtud derivada del intelecto superior. Participa de Dios tanto natural como sobrenaturalmente, y según esto último, tanto en la vida presente, por la fe y la profecía ${ }^{35}$, y asimismo la gracia, como en la futura, por la gloria ${ }^{36}$. Por esto el intelecto agente demuestra la existencia de Dios, pues es necesario que por encima del alma humana exista algún intelecto del que dependa el entender del intelecto agente ${ }^{37}$. Tras la muerte ya no conocerá como ahora, sino de otro modo ${ }^{38}$. La felicidad radica en la contemplación, la cual está vinculada al intelecto agente ${ }^{39}$.

En cuanto a los temas reales conocidos por el intelecto agente, el Doctor Común sostiene que éstos son todos los que se pueden conocer por medio de la abstracción ${ }^{40}$. En concreto, los primeros principios prácticos se captan por la

[34] "La luz del intelecto agente..., procede en el alma, sin duda, como del primer origen, de las sustancias separadas y principalmente de Dios". De Ver., q. 10, a. 6, co. "Cierta virtud participada de alguna sustancia superior, a saber, de Dios. Por lo cual el Filósofo dice que el intelecto agente es como cierto hábito y luz; y en el Salmo IV se dice: 'impresa está sobre nosotros la luz de tu rostro, Señor". Q.D. De Anima, q. un., a. 5, co. "Decimos que la luz del intelecto agente, de la que habla Aristóteles, es impresa en nosotros inmediatamente por Dios". Q.D. De Spiritualibus creaturis, q. 10, co. "Es llamado por Aristóteles luz recibida en nuestra alma por Dios". Ibid., q. 10, co. Cfr. también: De unitete intellectus, cap. 1. "Es verdad que el principio de la iluminación o ilustración es uno (único), es decir, alguna sustancia separada, a saber, Dios, según los católicos, o la inteligencia última, según Avicena”. Ibid., cap. V. Cfr. también: S. Theol., I ps., q. 79, a. 4 co.

[35] "Como hemos sostenido que el intelecto agente es cierta virtud participada en nuestras almas, como cierta luz, es necesario otra causa exterior de la que participe esta luz. Y a esta llamamos Dios, que instruye internamente, en cuanto que infunde la luz en el alma, y sobre la luz natural añade, por su beneplácito, luz copiosa para conocer esas cosas a las que no toca la razón natural, como es la luz de la fe y la luz de la profecía”.Q. D. De Anima, q. un., a. 5, ad 6.

[36] "Es propio de Dios iluminar a los hombres imprimiéndoles la luz natural del intelecto agente, y sobre ésta, la luz de la gracia y de la gloria”. Q.D. De Spiritualinus creaturis, q. 10, ad 1.

[37] "Es necesario que por encima del alma humana exista algún intelecto del que dependa su entender (el del intelecto agente)". Q.D. De spiritualibus creaturis, q. 10 co.

[38] Cfr. S.C. Gentes, 1. III, cap. 45, n. 9;

[39] Cfr. Q. D. De Anima, q. un., a. 5, co; In De Anima, III, lc. 10, n. 18.

[40] "La operación propia del intelecto agente es hacer las especies inteligibles en acto, abstrayéndolas de los fantasmas, por lo que se dice en el libro III De Anima que el intelecto agente es por lo que todo se hace". S. Theol., III ps., q. 9, a. 4, co. Cfr. asimismo: De Ver., q. 8, a. 3, co; Ibid., q. 18, a. 2, co; Ibid., q. 18, a. 5, co; Ibid., q. 18, a. 5, ad 6; Ibid., q. 19, a. 1, co; In Boetii De Trinitate, 1, 1, 3, co, 3; Ibid., 3, 6, 4, co, 2; S. C. Gentes, 1. II, cap. 60, n. 19; Ibid, 1. II, cap. 73, n. 9 ; Ibid, 1. II, cap. 76, n. 15; Ibid., 1. II, cap. 82, n. 3; Q. D. De Anima., q. un., a. 16, co; De Spiritualibus Creaturis, q. 9, co; Ibid., q. 10, co, y ad 4; In Posteriores Analiticorum, l. II, lc. 20, n. 12; In Physicorum, 1. VII, lc. 6, n. 8; De unitate intellectus, cap. 5; S. Theol., I ps., q. 4, ad 2. Ibid., I ps., q. 44, a. 3, ad 3; Ibid., I ps., q. 85, a. 1, ad 3; Ibid., I ps., q. 87, 1 co; Ibid., I ps , q. 87, a. 1, ad 2; Ibid., I ps. q. 88, a. 1, co. Ibid., III ps., q. 12, a. 1, co. Ibid., III ps., q. 12, a. 2, co

THÉMATA. Revista de Filosofía, $\mathrm{N}^{\circ} 50$ julio-diciembre (2014) pp.: 113-134

doi: 10.12795/themata.2014.i50.05 
luz del intelecto agente, como también los primeros principios de las ciencias especulativas ${ }^{41}$. Asimismo, que está en acto respecto de las especies sensibles, de las que abstrae, es decir, universaliza. También señala que el conocimiento de los transcendentales deriva del conocimiento abstractivo generado por intelecto agente ${ }^{42}$. Indica además que, aunque no conoce directamente a las sustancias separadas ni a Dios en esta vida, sí las conoce indirectamente, o sea, derivadamente de la abstracción. Destaca a la par que no es autointencional o reflexivo. Por lo demás, indica que el conocimiento de las causas físicas ${ }^{43}$, por ejemplo, es debido al intelecto agente. Asimismo, admite que el alma se conoce a sí misma a raíz de la abstracción ${ }^{44}$.

c) 'El intelecto agente es superior al posible y al resto de dimensiones noéticas humanas, a las que activa" ${ }^{45}$. Es raíz de todo el conocer humano hasta tal punto que sin él el hombre no puede conocer nada ${ }^{46}$. No es lo mismo que el hábito de los primeros principios, pues éstos (teóricos y prácticos) son un instrumento del intelecto agente ${ }^{47}$. Activa al posible mediante el hábito de los primeros principios, y asimismo, mediante las especies, pero él no tiene como algo propio tener o dejar de tener especies inteligibles, lo cual es propio del posible. El intelecto agente es acto (principio activo propio) y, por tanto, previo y superior, respecto del posible (que es potencial) ${ }^{48}$. Sin embargo, Tomás admite que el intelecto agente no siempre está en acto, pues sostiene que no siempre conoce. Más aún, que no conoce sin la concurrencia con el posible ${ }^{49}$. A la par, admite que el intelecto agente no basta él sólo para activar al posible, pues la perfección del posible no se logra tampoco sin Dios. Por lo demás, según el de Aquino, el intelecto agente no activa a la voluntad, ni directa ni indirectamente, pues ésta es activada por el posible ${ }^{50}$. Para conocer, el intelecto agente se sirve de la potencia cogitativa de la sensibilidad intermedia, potencia que dispone de los fantasmas. En orden a este punto sostiene que el que un hombre

[41] Cfr. De Ver., q. 18, a. 7, co; Ibid., q. 20, a. 6, ad 2; In De Anima, 1. II, lc. 11, n. 15.

[42] Cfr. In Boetii De Trinitate, 1, 1, 3, ad 3.

[43] Cfr. S. Theol., III, q. 12, a. 1, ad 1.

[44] "(El alma) ni siquiera a sí misma se puede conocer sino en cuanto se hace en acto por la especie abstraida de los fantasmas, pues así se conoce a sí misma por su acto”. S. Theol., I-II ps., q. 89, a. 2, co.

[45] Cfr. De Ver., q. 18, a. 8, ad 3; Ibid., q. 20, a. 2, ad 5; De substantiis separatis, 16.

[46] De Ver., q. 1, a. 1; Ibid., q. 8, a. 4, ad 4.

[47] Cfr. S.C. Gentes, 1. III, cap. 43, n. 2; Q. D. De Anima., q. un., a. 5, co; Q.D. De Spirit. Creat., q. 10 , co y ad 9 .

[48] Cfr. S.C. Gentes, 1. II, cap. 78, n. 10.

[49] "No hay que decir que el intelecto agente entienda separadamente del intelecto posible, sino que el hombre entiende por uno y otro". Q. D. De Spir. Creat., q. 10, ad 15.

[50] Cfr. S. C. Gentes, 1. II, cap. 76, n. 20.

THÉMATA. Revista de Filosofía, N50 julio-diciembre (2014) pp.: 113-134 doi: 10.12795/themata.2014.i50.05 
entienda mejor o peor que otro no se debe al entendimiento agente de cada uno, sino a la complexión de las potencias con soporte corporal de las que el intelecto agente abstrae (imaginación, memoria, cogitativa, etc.). Por último cabe señalar que, según el Aquinate, gracias al intelecto agente el hombre es libre y responsable, y por ello son posibles la ética y la política, lo cual significa que si es uno propiamente el que conoce y se entera, y no es pasivo respecto de la iluminación de otro, es uno mismo el que es libre de actuar de un modo o de otro en su vida privada y pública.

$$
* * *
$$

Discusión en torno al parecer de Tomás de Aquino sobre el intelecto agente. Si en este debate seguimos la precedente distinción tripartita, podemos distinguir tres aspectos:

a) Sobre la indole de 'potencia' del intelecto agente. Si se toma al intelecto agente como una facultad, y por serlo se lo considera un accidente, esto presenta una notable dificultad, pues si lo específico y distintivo del hombre respecto de los animales es lo 'racional' -que se puede entender como 'intelectual'- y el intelecto agente es raíz de ello, ¿cómo puede ser accidental lo distintivo del hombre? Por otra parte, 'potencia' denota pasividad, y el intelecto agente carece de ella. Si para paliar este problema, se añade que es potencia 'activa', la solución de la dificultad pasa por explicar que se entiende por tal, y en responder si una potencia puede ser 'nativamente' activa. Por lo demás, si se interpreta el intelecto agente como potencia, aparece el problema de explicar la correspondencia del intelecto agente con el posible, y también con los hábitos innatos y adquiridos. Por eso el de Aquino indica que el agente no es susceptible de hábitos (innatos, adquiridos e infusos) ${ }^{51}$.

De tomar al intelecto agente en sentido estricto como una potencia se entra en contradicción cuando se sostiene a la par que es en acto desde el inicio. Tal vez por esto Tomás de Aquino indicase algunas veces que el intelecto agente es una 'virtus', en el sentido medieval que este término tiene de 'fuerza', 'perfección', 'energía', pero no tomándolo propiamente como una 'potencia' o 'facultad'. Por lo demás, si el entendimiento agente es una 'potencia' del alma, no se puede predicar en rigor de él la imagen y semejanza divina, puesto que Dios es 'acto'; y por ello, tal potencia no participará de nada superior, a saber, de Dios. Añádase que si el intelecto agente es potencia o accidente del alma, cabría pensar que en el alma, por encima del intelecto agente, existe alguna dimensión real humana que pueda actuar como acto respecto de él, pero dado que él es cognoscitivo, tal dimensión también debería serlo, lo cual parece que estemos, o bien ante una explicación truncada, o bien ante un proceso al infinito en caso de admitir que tal dimensión también sea potencia.

[51] Cfr. In III Sent., d. 23, q. 1, a. 1, co; De Ver., q. 16, a. 1, ad 13; De Ver., q. 20, a. 2, ad 5.

THÉMATA. Revista de Filosofía, Nº50 julio-diciembre (2014) pp.: 113-134 doi: 10.12795/themata.2014.i50.05 
b) Sobre sus temas conocidos. Por un lado, cabe decir que Tomás de Aquino ciñe el conocer del intelecto agente en exceso a la abstracción. Ahora bien, no todo nuestro conocer depende de la abstracción, pues, es claro que las realidades inmateriales (los actos de conocer y de querer, los hábitos cognoscitivos y virtudes de la voluntad, las potencias, los hábitos innatos, los actos de ser personales, Dios) no son materiales; por tanto, respecto de ellos carece de sentido abstraer. Pero si es evidente que los conocemos, los conocemos de otro modo que no es el abstractivo. Es patente además que el mismo intelecto agente no es material, por tanto, no se puede conocer por abstracción, sino de otro modo, experiencialmente ${ }^{52}$. Asimismo si los trascendentales son distintos de los universales, tampoco se llegan a conocer por abstracción. Por otro lado, si se afirma que el entendimiento agente está abierto cognoscitivamente de modo natural a Dios, y, a distinción del entendimiento posible, es en acto, no se responde por qué no estamos siempre conociendo intuitivamente a Dios. Tomás podría replicar que, en efecto, él admite que el intelecto agente no está siempre en acto; pero esta tesis es problemática, pues no da razón de por qué Aristóteles, su descubridor, lo llamó 'agente' y 'siempre en acto'.

c) Sobre su relación con otras dimensiones noéticas humanas. Por una parte, si los hábitos innatos denotan perfección, no hay razón alguna para negar que éstos inhieran en el intelecto agente, que es acto, perfección por tanto. De lo contrario, se fuerza a incluirlos en el intelecto posible, pero dado que éste es pura potencia pasiva ('tabula rasa') carece de sentido decir que exista en él una perfección noética nativa. Por otro lado, parece que la voluntad no puede ser activada sólo por la acción del intelecto posible, no sólo porque también éste requiere ser activado, sino porque la voluntad requiere de una activación que no corra sólo por cuenta de su objeto, sino también del sujeto. Otra aporía la ofrece la tesis de que el entendimiento agente es cognoscitivo sólo cuando concurre con el posible, pues si es siempre en acto, cuando no concurriese con el posible no sería en acto, pero ¿es que acaso una potencia puede dotar de actividad a un acto? Perplejidad causa también la afirmación de que el hábito de los primeros principios sea un instrumento del intelecto agente, cuando Tomás admite que es un hábito del posible. Tampoco queda claro en el corpus tomista qué es lo que está vinculado con el intelecto agente, o los hábitos de los primeros principios (teóricos y prácticos), o lo tematizado por éstos, o ambas realidades. Asimismo, si el intelecto agente ilumina los primeros principios (especulativos y prácticos), y lo propio de él es iluminar especies, ¿acaso son los primeros principios (teóricos y prácticos) especies?, ¿cómo pueden ser primeros principios asuntos que son derivados de la abstracción, es decir, que ni son pri-

[52] "En la misma alma existe alguna virtud derivada del intelecto superior, por la que se puede ilustrar el fantasma. Y conocemos este experimento mientras percibimos que abstraemos formas universales de las condiciones particulares". S. Theol., I ps., q. 79, a. 4, co.

THÉMATA. Revista de Filosofía, №50 julio-diciembre (2014) pp.: 113-134 doi: 10.12795/themata.2014.i50.05 
meros ni principios? Y si ambas dimensiones son distintas y el intelecto agente las ilumina a ambas, ¿cómo las discierne? Como se puede apreciar, en el legado tomista quedan algunas paradojas, cuestiones abiertas y tesis sin armonizar.

\section{Las tesis principales de Buenaventura sobre el intelecto agente}

El Doctor Seráfico trató del intelecto agente en una distinción de su Comentario a las Sentencias ${ }^{53}$. En cuanto a su conocimiento histórico de los avatares de este tema en los filósofos que le precedieron, supo, desde luego, del hallazgo aristotélico del intelecto agente, y conoció asimismo otras posiciones que desestimó. En efecto, una de ellas distinguía los dos intelectos como dos sustancias; otra, como dos potencias; una tercera, como una potencia absoluta y otra comparada.

La vertiente hermenéutica árabe y judía consideró al intelecto agente como una 'sustancia separada'. Sobre este parecer Juan Fidenza distinguió dos modalidades: a) la de los que sostuvieron que el intelecto agente era una sustancia separada inferior a Dios mientras que el posible era una sustancia unida al hombre, tesis propia de Al-Kindi, Al-Farabí, Avicena, Avicebrón, Algazel y Maimónides. b) La de los que en esa distinción sustancial identificaban el intelecto agente con Dios y el posible con nuestra alma, parecer propio de Avempace y Averroes. El pensador toscano consideró falso al primer modo de 'sustancialismo', porque esta hipótesis admitía que tal sustancia iluminaba al hombre, pero según él, ninguna sustancia, salvo el mismo Dios, puede iluminar inmediatamente al alma humana. También consideró erróneo el segundo postulado, porque, según él, Dios nos ha dado una virtud activa, por la cual podemos ejercer nuestras propias operaciones.

Por lo que respecta a la opinión de los pensadores cristianos de su época que consideraban al intelecto agente como una 'potencia', distinta del posible, pero al fin y al cabo, 'potencia' (fue el caso - como se ha visto- de Tomás de Aquino), Buenaventura distinguió dos modalidades: a) La de quienes consideraron al intelecto posible como una potencia puramente material, y al agente como una potencia puramente formal; opinión propia de quienes aceptaron el llamado 'hilemorfismo universal': Alejandro de Hales, Juan de la Rochela y Mateo de Aquasparta. b) La de los que consideraron que el agente y el posible son dos diferencias del intelecto, es decir, de una única sustancia, ya que el po-

[53] Cfr. San Buenaventura, In Sententiarum, d. 24, p. 1, a. 2, q. 4, ed. Quaracchi, vol. II, 568. Cfr. al respecto: Cfr. V. MuÑz, "La iluminación del entendimiento agente en San Buenaventura", Revista Española de Filosofía Medieval, 9 (2002), 81-90. B. A. LuYckx, Die Erkennislehre Bonaventuras, Beiträge, XXIII, 3-4 (1923), 66-76 y 223; K. Werner, Die Psychologie und Erkennislehre des hl. Bonaventuras, 1876; E. LuTz, Die Psychologie Bonaventuras, 1909; C. Morón ARroyo, Abstraction und illumination. Grenzproblem der Mataphysik Bonaventuras, 1963; E. GiLson, La filosofía de San Buenaventura, Buenos Aires, Descée de Brouwer, 1948.

THÉMATA. Revista de Filosofía, №50 julio-diciembre (2014) pp.: 113-134 doi: 10.12795/themata.2014.i50.05 
sible está ordenado a tomar de las especies, y el agente a abstraerlas: parecer propio de Guillermo de Auvernia, Roberto Grosseteste, Pedro Olivi y Gonzalo de España. Tampoco estas interpretaciones le parecieron correctas a Buenaventura. La primera, porque defendía un materialismo o corporalismo para el intelecto posible. Pero de ser así, el intelecto posible -escribió- habría que ponerlo en todos y cada uno de los sentidos que tienen soporte material, lo cual es absurdo. La segunda, porque no admitía que, aunque el intelecto agente y el posible concurriesen en el mismo acto ${ }^{54}$, existiese entre ellos una distinción real, asunto que -como se ha visto- afirmaba Juan Fidenza.

Otro modo de comprender ambos intelectos que Buenaventura conoció, y que asimismo reprobó, fue el de quienes decían que uno de dos intelectos humanos es una 'potencia absoluta', mientras que el otro es una 'potencia comparada'. Esto se puede entender de dos modos según el pensador franciscano: a) De uno, según que se tome a los dos como una única potencia, con una mera distinción de comparación, pues el agente se tomaría en sí mismo, mientras que el posible se tomaría en cuanto que se une al cuerpo y a los fantasmas. Este parecer se puede fundar - dice- en Aristóteles, quien escribió que el agente 'siempre está en acto', mientras que el posible 'a veces sí y otras no'. Pero ese modo de decir -nos indica Buenaventura- 'deficit a veritate', porque el alma separada tiene intelecto agente y posible, y es claro que el posible no se dice tal en esa situación por comparación al cuerpo. b) De otro modo, en el sentido de que el agente se tome como potencia absoluta o completa, porque no le falta nada, y el posible como comparada o requerida de complemento, porque se ordena a tomar. Pero tampoco esta posición le pareció correcta, pues estimaba que el intelecto posible es potencia en sentido propio.

Las tesis principales que Buenaventura afirmó respecto del intelecto agente son las tres siguientes:

a) 'El intelecto agente es un hábito adquirido'. Para Juan Fidenza, este intelecto, desde luego, existe en el hombre ${ }^{55}$, y el modo más correcto de interpretar la distinción entre el intelecto agente y el posible, según su síntesis expositiva, es la de quienes tomaron a uno como 'potencia' y al otro como 'hábito'. Esta tesis fue propia de Mateo de Aquasparta y de Pedro Hispano. Esta posición también admitió históricamente dos lecturas: a) La de quienes compararon al agente a un 'hábito innato' y el posible a la 'potencia', opinión que Juan Fidenza atribuyó a los seguidores de Boecio, aunque también parece que fue la opinión

[54] En efecto, según él, ni el posible es puramente pasivo, ni el agente es del todo activo, pues no puede conocer si no es ayudado por las especies. Por lo cual, "ni el posible entiende sin el agente, ni el agente sin el posible”. Ibid., vol. II, 569 a.

[55] "Hay que creer indudablemente que no sólo se diese al alma humana el intelecto posible, sino también el agente; así, uno y otro son algo del alma”. In II Sententiarum, d. 24, p. 1, a. 2, q. 4, ed. Quaracchi, vol. II, 568.

THÉMATA. Revista de Filosofía, Nº50 julio-diciembre (2014) pp.: 113-134 doi: 10.12795/themata.2014.i50.05 
de Temistio. Según esto, tales autores pensaban que el agente es innatamente cognoscitivo. b) La de quienes compararon el agente a un hábito adquirido en el intelecto posible, en el sentido de que el agente fuese potencia habitual. El primero de los dos postulados anteriores Buenaventura no lo dio por bueno, porque, según él, no concordaba con lo que escribió el Filósofo, pues éste afirmó que el alma es como una tabula rasa, que no tiene nada habitualmente conocido, sino que lo adquiere todo mediante el sentido y la experiencia. En cambio, se sumó al segundo parecer, porque lo consideró el más probable y verdadero y lo apoyó en Aristóteles, quien dejó escrito que el agente es 'como un hábito'.

b) 'El intelecto agente concurre inseparablemente con el posible ${ }^{56}$. La opinión bonaventuriana de que el agente y el posible concurren inseparablemente para conocer fue compartida en su siglo por Alberto Magno, Tomás de Aquino y Ricardo de Mediavilla, y posteriormente por otros comentadores, por ejemplo, Silvestre de Ferrara y Rodrigo de Sancta Ella en el s. XV, y Francisco de Toledo en el s. XVI. Posteriormente muchos comentadores admitieron que de cara a la intelección lo que concurren son las especies inteligibles y el intelecto agente. En cualquier caso, estas hipótesis implican que no se puede explicar lo superior -el acto- sin lo inferior -la potencia-, pero esta posición, por una parte, no es aristotélica, porque el de Estagira explicó la potencia por correlación al acto, no a la inversa, y, por otra parte, no parece ajustarse a la realidad, pues equivale a admitir que inicialmente el intelecto agente no sea cognoscitivo y que después, en concurrencia con el posible, lo sea, lo cual equivale a educir el conocer de la falta de conocer, lo cual no es justificable.

c) 'El papel del intelecto agente es abstractivo'. Buenaventura vinculó tanto el intelecto agente a su función abstractiva que acabó admitiendo que sin las realidades sensibles y sin los sentidos es imposible conocer: "si el agente puede formar o abstraer el conocimiento en el intelecto posible, sin embargo, su operación depende tanto de la certeza de la realidad externa como del sentido interior; ya que faltando la realidad perece la ciencia, y faltando el sentido, es necesario que falte la ciencia según aquel sentido" ${ }^{57}$. Si la tesis precedente comporta el intento de explicar lo superior -el intelecto agente- en vinculación con lo inferior -el intelecto posible-, esta tesis ahonda en la supeditación de lo superior -el intelecto agente- a una dimensión humana todavía inferior -las especies-. Pero si la tesis anterior supone una petición de principio, no menos la exige ésta, pues ambas admiten implícitamente que el conocer surja de lo que no conoce.

[56] "El agente y el posible son dos diferencias, concurrentes en una operación completa". Ibid., II, 571 b. [57] San Buenaventura, Commentarius in Ecclesiasten, c. VII, Claras Aquas, Typ. Collegii S. Bonaventurae, 1893, vol. VI, 54 b.

THÉMATA. Revista de Filosofía, $\mathrm{N}^{\circ} 50$ julio-diciembre (2014) pp.: 113-134 doi: 10.12795/themata.2014.i50.05 
Discusión en torno al parecer de Buenaventura sobre el intelecto agente. Resumamos en tres tesis su parecer y revisemos su contenido.

a) Respecto de su primera tesis, es cierto que el estagirita escribió que el intelecto agente es 'a manera de una disposición habitual', pero eso no equivale a sostener que sea un hábito (ni adquirido ni innato). Si el intelecto agente fuese un hábito del intelecto posible, es claro que no podría ser innato, asunto que Juan Fidenza advirtió, porque una 'tabula rasa' no puede tener nativamente un hábito innato, ya que hábito denota perfección, dotación perfectiva noética en este caso- desde el inicio. En cambio, admitió que el intelecto agente es un hábito adquirido del intelecto posible. Pero esta tesis ofrece un problema: ¿cómo una potencia que es pasiva pasa de la potencia al acto sin ser activada por un acto previo. Pero esto tal vez no le causara ninguna perplejidad al Doctor Seráfico, pues -siguiendo a Agustín de Hipona ${ }^{58}$ - admitió que nuestra alma es iluminada por Dios ${ }^{59}$.

b) En cuanto a la segunda tesis, que el intelecto agente ejerza su acto en obligada concurrencia con el posible, parece paradójico, pues ¿cómo puede ser que el origen del conocer no sea cognoscitivo? Afirmar esa hipótesis parece suponer que el intelecto agente no sea la raíz del conocer humano. Pero si no lo es, su función debe ser suplida por una realidad extrínseca, seguramente la iluminación divina, tesis cercana a la del sustancialismo árabe, sólo que mientras que en ésta se recurre a Dios para que ilumine constantemente, Buenaventura recurre al ser divino al menos para el impulso noético inicial.

c) Por lo que se refiere a la tercera tesis, a saber, que el intelecto agente se dedique en exclusiva a abstraer, no parece apropiada, porque si se estima que el agente es lo más crucial del alma humana, ¿por qué recurrir a lo inferior, a los sentidos, para dar cuenta cabal de él?

[58] Cfr. P. Mandonnet, "L'Augustinisme bonaventurien", Bulletin thomiste, 1 (1926), 48-54. También comparte con San Agustín el 'ejemplarismo'. Cfr. J. M. Bissen, "L'exemplarisme divin selon saint Bonaventure”, Etudes de Philosophie Medievale, 10, París, 1929.

[59] Cfr. V. Ch. Bigi, "La dottrina della luce in S. Bonaventura", Divus Thomas, 64 (1961), 395-422.

THÉMATA. Revista de Filosofía, Nº50 julio-diciembre (2014) pp.: 113-134

doi: 10.12795/themata.2014.i50.05 


\section{Las tesis más relevantes de L. Polo sobre el intelecto agente}

Leonardo Polo ha tratado del intelecto agente desde el inicio hasta el final de su producción. En efecto, abordó este tema en algunos de sus primeros escritos como El acceso al ser ${ }^{60}, E l s e r^{61}$ y Evidencia y realidad en Descartes $^{62}$; también en otros posteriores como Lecciones de psicología clásica $^{63}$ curso publicado mucho después de impartirlo, en su amplio Curso de teoría del conocimiento ${ }^{64}$, o en otros libros como Hegel y el posthegelianismo ${ }^{65}$, Sobre la existencia cristiana ${ }^{66}$, La persona humana y su crecimiento ${ }^{67}$, Persona y libertad $^{68}$, Nominalismo, idealismo y realismo ${ }^{69}$, y asimismo en los estudios que se encuadran en su último periodo, como los dos volúmenes de Antropología trascendental ${ }^{70}$.

Polo conoció la tradición filosófica respecto de este punto en sus grandes hitos, a saber: la interpretación del intelecto agente como 'sustancia separada', cuyo mejor representante fue Averroes; el considerarlo como una 'potencia' del alma, cuyo autor más representativo fue Tomás de Aquino; y asimismo las versiones escotista y nominalista del 'intellectus agens'. Estos puntos de vista fueron rebatidos por este reciente pensador. Desconoció, en cambio, además de otras opiniones menores, la interpretación de él como hábito adquirido o innato, salvo al final de su vida, en que se alegró de saber que Teodorico el Teutónico lo hubiese considerarlo como la sustancia humana, entendiendo a ésta como 'acto por su propia entidad'. Seguramente la posición de éste autor es la que más afinidad guarda con la poliana, y, en segundo lugar la propia de Alfonso de Toledo, porque éste pensador lo consideró un 'hábito innato'. De seguro se objetará que ambas posiciones son irreductibles, pero debe tenerse en cuenta que en Polo hay una evolución al respecto, pues si bien inicialmente consideraba que el papel del intelecto agente es el de activar a la inteligencia, iluminar los objetos de la sensibilidad intermedia y abstraer, posteriormente

[60] Cfr. Polo, L., El acceso al ser, Pamplona, Eunsa, 1964, $2004^{2}$.

[61] Cfr. El ser, I: la existencia extramental, Pamplona, Eunsa, 1966,1997².

[62] Cfr. Evidencia y realidad en Descartes, Rialp, Madrid, 1963, Pamplona, Eunsa, 1996².

[63] Cfr. Lecciones de psicología clásica, Pamplona, Eunsa, 2009.

[64] Cfr. Curso de teoría del conocimiento, Pamplona, Eunsa, vols., I-IV, 1984-2004.

[65] Cfr. Hegel y el posthegelianismo, Universidad de Piura, Piura, 1985, Pamplona, Eunsa, 1999.

[66] Cfr. Sobre la existencia cristiana, Pamplona, Eunsa, 1996; $2^{\mathrm{a}}$ ed. con el título Sobre la originalidad de la concepción cristiana de la existencia, Pamplona, Eunsa, 2010.

[67] Cfr. La persona humana y su crecimiento, Pamplona, Eunsa, 1996, $1999^{2}$.

[68] Cfr. Persona y libertad, Pamplona, Eunsa, 2007.

[69] Cfr. Nominalismo, idealismo y realismo, Pamplona, Eunsa, 1997, 2001².

[70] Cfr. Antropología trascendental, I. La persona humana, Pamplona, Eunsa, 1999, 2003², y Antropología trascendental, II. La esencia de la persona humana, Pamplona, Eunsa, 2003.

THÉMATA. Revista de Filosofía, №50 julio-diciembre (2014) pp.: 113-134

doi: 10.12795/themata.2014.i50.05 
pensó que este papel hay que reservárselo a un hábito innato, en concreto, a la sindéresis, no comprometiendo en directo al intelecto agente en tareas inferiores, y así dejarlo libre para corresponderse a modo de búsqueda con su tema propio, el cual es superior a él, a saber, el ser divino.

En el tratamiento del intelecto agente por parte de Polo se pueden distinguir tres aspectos: su carácter trascendental, es decir, el ser un radical de los que conforman el acto de ser personal humano; su tema propio, distinto de todas las demás instancias noéticas humanas, a saber, el Dios personal, más aún, pluripersonal; y su correspondencia con las otras dimensiones cognoscitivas humanas, todas las cuales son inferiores a él. Expongamos a continuación estas tres tesis centrales.

a) 'El intelecto agente es un trascendental personal del acto de ser personal humano ${ }^{71}$. La persona humana no sólo 'tiene' conocer -en su razón, en sus sentidos...-, sino que lo 'es', y tal conocer es el intelecto agente. Como se ha adelantado, para Polo, el intelecto agente forma parte del acto de ser del hombre ${ }^{72}$. Es el acto 'primario' en el hombre, no el acto de ser como 'primer principio', puesto que la persona humana no es un primer principio ${ }^{73}$. En efecto, los primeros principios reales son eso, el fundamento de la realidad, pero el intelecto agente no fundamenta nada, porque el conocer es una denominación extrínseca para las cosas. Por eso, "la persona no es la sustancia clásica ni el sujeto de la filosofía moderna. El intelecto agente tampoco es una cosa ni la otra"74. El intelecto agente es acto, "el acto de los inteligibles en acto"75, pero acto como acto de ser personal, no como acto de ser principial, fundante y extramental. Ahora bien, el acto de ser personal es superior al que no es persona. Las notas distintivas del acto de ser personal son -según Polo- la coexistencia libre, el conocer y el amar personales. El intelecto agente equivale a uno de esos radicales, el conocer personal, que no existe desvinculado de los demás. En suma, lo que precede indica que "el intellectus ut co-actus no es un único acto"76, o también,

[71] Cfr. Polo, L., "La persona como ser cognoscente", Studia Poliana, 8 (2006) 53-72.

[72] "El intelecto agente es el acto intelectual radical o personal". Curso de teoría, IV/2, Pamplona, Eunsa, 1994, 141. "Estimo que el intelecto agente... como acto donal es un trascendental personal. Como acto de los inteligibles actuales, es superior a lo inteligible actual. Como iluminador de lo intelectual, es superior a lo que ilumina y a la iluminación (la iluminación es el hábito)... El carácter donal, personal, del acto intelectual radical del hombre, da razón de lo que los filósofos modernos llaman sujeto y es superior a la interpretación reflexiva del pensar". Ibid., 143.

[73] "El núcleo del saber no es el principio trascendental. Justamente conviene llamar principio a aquello de que primariamente se distingue el núcleo del saber en el plano trascendental. El principio trascendental es el ser". El acceso al ser, ed. cit., 54.

[74] Curso de teoría del conocimiento, I, $2^{\mathrm{a}}$ ed., 234.

[75] En el Curso de teoría del conocimiento, II, se repite muchas veces esta expresión. Cfr. $3^{\mathrm{a}}$ ed., 158, 170, 204, 225, 232, 233, 236, etc.

[76] Antropología, I, ed. cit., 180.

THÉMATA. Revista de Filosofía, Nº50 julio-diciembre (2014) pp.: 113-134 doi: 10.12795/themata.2014.i50.05 
que el acto de ser personal humano no es simple (simple, sólo es Dios). Somos una persona, pero el acto de ser personal humano admite composición, pues el amar personal, por superior, es irreductible al conocer personal, y éste, a su vez, a la coexistencia libre personal. Dicho de otro modo: el acto de ser humano es co-acto de ser.

b) 'El tema del intelecto agente es Dios ${ }^{77}$. El tema del conocer humano superior no puede ser nada inferior a él. Este tema tampoco puede ser el mismo intellectus agens, porque ningún conocer humano es reflexivo respecto de sí, ya que método cognoscitivo y tema conocido constituyen en las criaturas una dualidad que no puede ser reducida a identidad ${ }^{78}$. Ahora bien, como tal conocer no puede carecer de tema (sería absurdo ${ }^{79}$ ), Polo indica que "el intellectus ut co-actus se corresponde con un tema superior y distinto" 80 , pero de su misma índole, a saber, personal, pues si el intelecto agente es personal, dado que una persona es apertura o relación personal respecto de otra persona, el tema del intelecto agente no puede ser sino personal, es decir, una persona cognoscente distinta. En efecto, si el conocer del intelecto agente es de rango personal, su tema no puede ser impersonal. A esto Polo añade que su tema es el ser divino personal ${ }^{81}$. En suma, para este pensador, el hábito de sabiduría es el método noético que alcanza a conocer al intelecto agente como tema, y éste es, a su vez, el método cuyo tema es el ser divino ${ }^{82}$. Por lo demás, según Polo, este conocer

[77] "El tema correspondiente al intellectus ut co-actus no se alcanza en la tercera dimensión del abandono del límite. Por tanto, debe decirse que dicho tema es inabarcable. La inabarcabilidad alude a Dios". Antropología, I, 182. En nota al pié añade: "desde luego, la luz divina es superior a la humana. Por consiguiente, la cuestión del tema correspondiente al intellectus ut co-actus se resuelve, en definitiva, de acuerdo con la expresión paulina: 'conoceré como soy conocido", nota 46. Y más adelante: "La primera dimensión advierte el Origen como insondable; la tercera reserva al intellectus ut co-actus su tema (no lo alcanza), pero es solidaria temáticamente con el intelecto personal (no con el tema de éste)", Ibid., 195.

[78] "El intellectus ut co-actus es el núcleo del saber, desde el cual -radicalmente- se ejercen las operaciones y los hábitos; pero él no es estrictamente ninguno de ellos, por ser el acto intelectual superior. Que la persona sea el acto intelectual superior no comporta la identidad intelectual, pues la identidad es exclusiva de Dios". Antropología, I, ed. cit., 224.

[79] Antropología, I, ed. cit., 224-225.

[80] Antropología, I, ed. cit., 160.

[81] Polo intenta "precisar en lo posible de qué manera Dios es el tema propio de éste (intelecto agente). Desde luego, el conocimiento de Dios como tema del intellectus ut co-actus es distinto de la vías demostrativas, las cuales concluyen en Dios según el primer sentido del est", Antropología, I, 154-155. Cfr. asimismo: Polo, L., "El descubrimiento de Dios desde el hombre", Studia Poliana, 1 (1999) 11-24.

[82] "Dios es el tema del acto cognoscitivo superior humano en tanto que en ese tema está incluido también, temáticamente, dicho acto cognoscitivo: la persona conoce a Dios en tanto que conoce como Dios la conoce. En este sentido, puede hablarse de la comunicación donal de un tema doble: Dios e intelecto personal humano. Así pues, la llamada contemplación beatífica de Dios implica el propio conocimiento, sin que sea necesaria una reflexión que arranque de éste". Antropología, I, ed. cit., 230.

THÉMATA. Revista de Filosofía, $\mathrm{N}^{\circ} 50$ julio-diciembre (2014) pp.: 113-134

doi: 10.12795/themata.2014.i50.05 
es elevado por Dios en la presente situación, y será glorificado por él en la vida poshistórica ${ }^{83}$.

c) 'El intelecto agente es el conocer humano superior'. En cuanto a la función del intelecto agente respecto de las instancias cognoscitivas humanas menores a él, Polo niega que su papel se reduzca a iluminar los fantasmas ${ }^{84}$, porque de ser así, su tarea sería coadyuvante y, en consecuencia, un conocer carente de tema propio ${ }^{85}$. Como se ha adelantado, inicialmente sostenía que también ese papel es propio de intellectus agens, pero en sus últimos escritos indica que esa tarea es propia de un hábito innato del que se sirve el intelecto agente a modo de instrumento ${ }^{86}$, en concreto, ese que la tradición medieval denominó sindéresis. Por tanto, el intelecto agente responde indirectamente (a través de la sindéresis) de la activación del intelecto posible suscitando sus actos y rindiéndolo cada vez más activo mediante los hábitos adquiridos ${ }^{87}$. En

[83] “el conocimiento 'facial' de Dios es un don divino en el que está incluido el conocimiento del propio intelecto personal. Dios es el tema del acto cognoscitivo superior humano en tanto que en ese tema está incluido también, temáticamente, dicho acto cognoscitivo: la persona conoce a Dios en tanto que conoce como Dios la conoce. En este sentido, puede hablarse de la comunicación donal de un tema doble: Dios e intelecto personal humano. Así pues, la llamada contemplación beatífica de Dios implica el propio conocimiento, sin que sea necesaria una reflexión que arranque de éste". Antropología, I, 226. En nota añade: "si el propio conocimiento arrancara de sí reflexivamente, el hombre no conocería nunca a Dios. Sin conocer a Dios, la persona creada no se conoce; pero ese conocerse le es dado por Dios según la elevación del lumen gloriae".

[84] La libertad trascendental, Pamplona, Eunsa, 2005, 89.

[85] Antropología, I, ed. cit., 224-225.

[86] "En Tomás de Aquino hay netas alusiones a la cuestión; por ejemplo, llama al hábito de los primeros principios 'habilitas intellectus agentis'. El hábito es un tener en propio, una adquisición que está estrictamente en la facultad, pero es una habilitas, una manera de iluminar del intelecto agente". Curso de teoría del conocimiento, III, $2^{\mathrm{a}}$ ed., 8. Y más adelante: "Santo Tomás advierte que el intelecto agente tiene que ver con los hábitos, pero no desarrolla esta observación. El desarrollo que aquí se propone conecta con una noción tomista primordial". Ibid., $2^{\text {a }}$ ed., 11. "Los hábitos son el perfeccionamiento, el reforzamiento de la facultad en cuanto tal. Referidos al intelecto agente, los hábitos son su habilitas. Las operaciones intelectuales siguen en tanto que la potencia intelectual está perfeccionada por los hábitos. En este sentido puede decirse que siguen también al intelecto agente de acuerdo con su habilitas". Ibid., II, $3^{a}$ ed., 165. "No parece que el valor iluminante del intelecto agente se reduzca a iluminar los objetos sensibles (ni a las operaciones), no es preciso admitir que dicha iluminación corra directamente a su cargo: es perfectamente posible que dicha iluminación tenga lugar de modo habitual. Esto abre el amplio campo temático de los hábitos innatos". Antropología, I, 153.

[87] "El intelecto agente es más de lo que dice Aristóteles (no es lo que dice Aristóteles), quien no ha visto su valor iluminante de actos y, por tanto, no lo ha puesto en relación con el conocimiento habitual. Y como estimo que hay que hacerlo, lo formulo axiomáticamente: el conocimiento habitual es debido al intelecto agente. El axioma de los hábitos dice que la inteligencia es susceptible de hábitos; ahora se añade: los hábitos son posibles por el intelecto agente. Así se completa la formulación del axioma. Pero la segunda parte de la formulación no es aristotélica... Por consiguiente, ha de iluminar a la presencia mental (la operación inmanente) en su ocultamiento (porque ella no se presenta a sí misma, sino al objeto conocido). No por eso se eliminan los actos de la inteligencia

THÉMATA. Revista de Filosofía, №50 julio-diciembre (2014) pp.: 113-134 doi: 10.12795/themata.2014.i50.05 
efecto, es acto respecto de todo otro conocer intelectual humano inferior ${ }^{88}$, pero, precisamente porque se puede dar el acto sin la activación de lo potencial, se puede explicar el intelecto agente al margen de la activación de la inteligencia. El intelecto en acto está al margen de toda operación y existe aunque aquella no exista. Él es el auténtico a priori del conocimiento humano porque el entendimiento agente constituye la inteligibilidad en acto: "la inteligencia humana es imposible sin intelecto agente. El intelecto agente es un acto y por ello es superior a la inteligencia" 89 . Polo añade que debe acompañar al intelecto posible en todo su recorrido, es decir, en toda su activación, ya sea a modo de operaciones inmanentes o de hábitos adquiridos ${ }^{90}$. Así, "cambia también la relación del intelecto agente con la inteligencia como potencia... La nueva formulación de la noción de intelecto agente acentúa la importancia de la noción de hábito. El hábito como perfeccionamiento de la facultad por la posesión intrínseca de su operación (no del télos de su operación: el objeto es poseído sólo por la operación), se debe a la iluminación del intelecto agente (lo poseído intrínsecamente por la facultad es la operación iluminada). La inteligencia así entendida es una facultad creciente (potencia del esse hominis, no el intelecto

ni son substituidos por el sujeto. El sujeto comparece en el momento justo y como tiene que comparecer, es decir, sin eliminar la operación intelectual ni los hábitos; al revés, justificando los hábitos. Además, en este planteamiento el intelecto agente deja de ser una mera pieza teórica colocada en el inicio de la actividad de la inteligencia y se entiende como la unidad del esse hominis en orden al crecimiento intelectual". Curso de teoría del conocimiento, III, $2^{\mathrm{a}}$ ed., 12.

[88] "El intelecto agente preside la intelección" Antropología, I, 52. "La inteligencia humana sin intelecto agente no podría pasar al acto, no podría ser principio operativo. Dicho de otro modo, la inteligencia no es una facultad sola: requiere un «acompañante», un acto que concurre con su carácter estrictamente potencial". Curso de teoría del conocimiento, II, ed. cit., 155.

[89] Curso de teoría del conocimiento, II, $3^{\mathrm{a}}$ ed., 170.

[90] "Si los hábitos son... actos y correlativamente perfecciones de la facultad, entonces los hábitos tienen que ser iluminaciones de las operaciones por el intelecto agente cuando se trata de hábitos intelectuales... De ahí derivan los hábitos, y no causalmente, sino de acuerdo con la índole del intelecto. El intelecto es la luz, y esto no es metafórico porque el intelecto es más luz que la luz física". La libertad trascendental, ed. cit., 89. Y en otra parte añade: "El intelecto agente es más de lo que dice Aristóteles (no es lo que dice Aristóteles), quien no ha visto su valor iluminante de actos y, por tanto, no lo ha puesto en relación con el conocimiento habitual. Y como estimo que hay que hacerlo, lo formulo axiomáticamente: el conocimiento habitual es debido al intelecto agente. El axioma de los hábitos dice que la inteligencia es susceptible de hábitos; ahora se añade: los hábitos son posibles por el intelecto agente. Así se completa la formulación del axioma. Pero la segunda parte de la formulación no es aristotélica... Por consiguiente, ha de iluminar a la presencia mental (la operación inmanente) en su ocultamiento (porque ella no se presenta a sí misma, sino al objeto conocido). No por eso se eliminan los actos de la inteligencia ni son substituidos por el sujeto. El sujeto comparece en el momento justo y como tiene que comparecer, es decir, sin eliminar la operación intelectual ni los hábitos; al revés, justificando los hábitos. Además, en este planteamiento el intelecto agente deja de ser una mera pieza teórica colocada en el inicio de la actividad de la inteligencia y se entiende como la unidad del esse hominis en orden al crecimiento intelectual". Curso de teoría del conocimiento, III, $2^{\mathrm{a}}$ ed., 12. "La inteligencia adquiere hábitos porque el intelecto agente ilumina su operar". Ibid., 21.

THÉMATA. Revista de Filosofía, Nº50 julio-diciembre (2014) pp.: 113-134

doi: 10.12795/themata.2014.i50.05 
pasivo del naturalismo árabe), capaz de operaciones diversas, más de las que admite el aristotelismo" "91. Por otra parte, también "los hábitos innatos dependen del intelecto agente" ${ }^{2}$.

Discusión en torno al parecer de L. Polo sobre el intelecto agente. Estamos de acuerdo con las tres tesis en que hemos resumido el parecer de este pensador respecto del intelecto agente. Si se rastrean todos sus textos, se nota, en primer lugar, una excelente prosecución del hallazgo aristotélico respecto de la índole, del tema del intelecto agente y de la correspondencia de este intelecto con otras dimensiones noéticas humanas. Pero junto a ello se echan en falta dos tareas por realizar, siendo una de tipo formal y otra de contenido:

a) Una, la de forma, es la carencia de análisis y comentario en las obras polianas a las notas con que Aristóteles describió al intellectus agens, entre otras, las de 'separable', 'sin mezcla', 'impasible', 'acto por su propia entidad'. Pero como la filosofía de Leonardo Polo no sigue ni el método analítico ni la hermenéutica textual, y como ambos métodos racionales son improcedentes para descubrir lo que supera a la razón, a saber, el propio conocer personal o intelecto agente, esta aparente carencia es excusable. Con todo, es claro que para Polo el intelecto agente es 'separado' de cualquier objeto conocido como idea; que es 'sin mezcla', es decir, carente de órgano corporal; que es 'impasible', a distinción de la inteligencia o intelecto 'paciente', que pasa de la potencia al acto. En cuanto a la expresión aristotélica 'es acto por su propia entidad', Polo la entiende en el sentido de que el intelecto agente siempre está en acto, puesto que equivale al co-acto de ser personal humano. Por lo demás, también advierte que es 'más excelso el agente que el paciente'.

[91] Curso de teoría del conocimiento, III, $2^{\mathrm{a}}$ ed., 20. “¿Cómo un principio finito puede ser operativamente infinito? Es evidente que no puede serlo él sólo; por lo tanto, el acompañamiento del intelecto agente no puede estar sólo en el inicio, en el suministro de especies impresas. Por así decirlo, el intelecto agente tiene que acompañar a la inteligencia en el mantenimiento de su operatividad". Curso de teoría del conocimiento, II, $3^{\mathrm{a}}$ ed., 165. Más arriba había escrito: “¿cómo puede predicarse la infinitud de la operatividad y no de la facultad? Esta pregunta nos orienta, por un lado, hacia el intelecto agente, y, por otro, hacia la noción de hábito". Ibid., II, $3^{a}$ ed., 160. Cfr. también: Ibid., III, $2^{\text {a ed., }}$ 8. "El conocimiento habitual es una iluminación debida al intelecto agente -el cual es asimilable al actus essendi humano-". Nominalismo, idealismo y realismo, ed. cit., 187.

[92] Antropología, I, ed. cit., 154. Y en nota al pié especifica: "según el planteamiento propuesto, el llamado intelecto agente, el lumen intellectus, es un trascendental personal. Por eso es preferible denominarlo intellectus ut co-actus o intelecto personal". Ibid., nota 4.

THÉMATA. Revista de Filosofía, Nº50 julio-diciembre (2014) pp.: 113-134 doi: 10.12795/themata.2014.i50.05 
b) Otra carencia, la de contenido, se refiere a una ausencia de explicación de las sentencias que el de Estagira afirmó del noûs poietikós en la última parte de su célebre pasaje De Anima, III, 5 (Bk 430 a 10-24), a saber:

1) 'Desde el punto de vista de cada individuo la ciencia en potencia es anterior en cuanto al tiempo, pero desde el punto de vista del universo en general no es anterior ni siquiera en cuanto al tiempo'. Sin embargo, aunque en los textos polianos no haya explicación directa de esta sentencia aristotélica, es claro que como en la filosofía de este pensador el acto es previo y condición de posibilidad de lo potencial y de su activación, ésta se puede entender en el sentido de que el intelecto agente es previo temporal y ontológicamente al posible.

2) 'No ocurre, desde luego, que el intelecto entienda a veces y a veces deje de entender', lo cual abre la pregunta de que, dado que Polo hace equivaler el intelecto agente al acto de ser humano, que éste existe desde el inicio, y que, por cognoscente, no puede carecer de tema, ¿cómo es la apertura cognoscitiva del intelecto a Dios desde el inicio de su existencia?, pues, desde luego, aunque inicialmente sea búsqueda, somos inconscientes de ello.

3) 'Una vez separado es sólo aquello que en realidad es y únicamente esto es inmortal y eterno'. Polo distingue entre inmortalidad y eternidad. La primera la predica del alma y de sus facultades inmateriales -inteligencia y voluntad-. La segunda la predica de Dios, no en el tradicional sentido de que 'Dios es eterno', sino de que 'la eternidad es Dios'. Pero entre el alma y Dios está la persona humana, el espíritu, el acto de ser, y considera que éste es realmente distinto de la esencia humana, a la que él llama 'alma'. Por tanto, de la persona humana no cabe decir ni que sea inmortal ni que sea eterna por naturaleza. De modo que falta caracterizar en la obra de Polo el modo futurizante de la persona humana, la cual, está por encima de la pervivencia en el tiempo sucesivo -inmortalidad-y por debajo de la carencia absoluta de tiempo -eternidad-.

4) 'Nosotros, sin embargo, no somos capaces de recordarlo, porque tal principio es impasible, mientras que el intelecto pasivo es corruptible y sin él nada entiende'. A la primera parte de esta sentencia cabe decir que en la obra de Polo falta también por responder a la siguiente cuestión: ¿por qué somos inicialmente conocer y no somos conscientes de que lo somos? Exponiéndolo de modo poliano: si el hábito de sabiduría es el conocer humano que alcanza al intelecto agente como tema, y tal hábito es innato y cognoscente, ¿por qué no conoce al intelecto agente desde el primer instante o inicio de la existencia humana?, es decir, ¿por qué no somos conscientes de que cada uno somos un conocer personal distinto desde el inicio? A la segunda parte del enunciado 
aristotélico cabe decir, que aunque Polo no precise su significado, seguramente lo entendería en el sentido de que, por una parte, el intelecto pasivo corruptible se refiere al sentido con base orgánica, y por otra, sin el intelecto agente el hombre no puede conocer nada.

\section{A modo de conclusión}

Podemos resumir en tres observaciones las posiciones estudiadas respecto del intelecto agente de los tres aludidos pensadores, Tomás de Aquino, Buenaventura y Leonardo Polo.

1) La tesis de Tomas de Aquino acerca de que el intelecto agente sea una 'potencia' sólo es salvable si ese término no se toma en sentido estricto, a saber, como facultad del alma humana. Es aceptable, por tanto, si se toma de modo analógico, es decir, como una 'virtud' o 'perfección' humana. Con todo, aún entendiéndola así, hay textos tomistas que reducen en exceso el alcance de dicha perfección, porque en ellos se afirma que es 'algo', 'parte', o 'accidente' del alma, no que sea el acto respecto de ella. Se echa, pues, de menos que quien descubriese la distinción real entre actus essendi y essentia en la realidad creada, no la advirtiese en el conocimiento humano, que, por creado, también es compuesto, más que al modo acto-potencial, al estilo de acto de ser-esencia.

2) No es aceptable la versión del intelecto agente como 'hábito adquirido' del posible, propia de Buenaventura, porque no da razón natural de la activación del intelecto posible; no responde, por tanto, al hallazgo aristotélico, y porque en sentido estricto, no admite la distinción real entre el intelecto agente y el posible, es decir, la dualidad radical y jerárquica de dimensiones humanas, en este caso noéticas.

3) La tesis de Leonardo Polo que toma como equivalente al intellectus agens con el acto de ser personal humano está en concordancia con el hallazgo aristotélico y lo prosigue, a la par que es coherente con la distinción real tomista entre acto de ser y esencia en el hombre y la prosigue. Y, a la vez, rectifica por elevación el planteamiento bonaventuriano al indicar que el intelecto agente se sirve de un hábito innato -no adquirido- para activar al intelecto posible y abstraer de las especies sensibles, a saber, la sindéresis, hábito al que Polo esclarece en mayor medida que los pensadores medievales que lo tuvieron en cuenta. Pero también el planteamiento poliano es susceptible de prosecución, al menos, en las líneas que se han indicado. 